\title{
Optimization Model of Resources Reallocation for Project Group under the Precondition of Resources Supply Scarcity
}

\author{
CHANG Chunguang ${ }^{1, ~ a, ~ Q I ~ M i n g h a o ~}{ }^{2, b}$, LUO Jingyu ${ }^{3, b}$ and YANG Shuang ${ }^{1, c}$ \\ ${ }^{1}$ School of Management, Shenyang Jianzhu University, Shenyang 110168, China \\ ${ }^{2}$ China Construction Eighth Engineering Division. CROP.LTD Tianjin Branch, Tianjin 300452, China \\ ${ }^{3}$ School of Information and Control Engineering, Shenyang Jianzhu University, Shenyang 110168 , \\ China \\ achang_chunguang@163.com, ${ }^{\text {bccg7788@sohu.com, }{ }^{c} c c g 777 @ s o h u . c o m ~}$
}

Keywords: Construction management; Project group; Optimization model; Resource reallocation

\begin{abstract}
The construction process of project group is full of uncertain factors, large numbers of resources are required, and it is easy to lack of certain resources. Based on programming theory, the project group resource reallocation optimization model is established when supplied resource quantities are insufficient. By applying programming theory, a linear programming model including labor, material resource reallocation is established, it regards the shortest delaying construction period and minimum extra increased cost as the objective function. It guarantees the rational reallocation of resources. Through actual example analysis, how to optimize the configuration of the actual project group when the situation in which insufficient resources supply occurs is vadilated.
\end{abstract}

\section{Introduction}

During the construction process among project group, many construction procedures of several projects need to be considered together, and many categories of materials often appear lacking. To avoid working waiting and shutdown, projects' plans and scheduling schemes should be adapted according to practical condition, feasible measures should be applied quickly so as to reallocating the limited sources to varied projects within project group. Thus, projects' plans and scheduling schemes can be implemented in an orderly way. However, extra time delay and expense will appear. Under this condition, how to realize dynamic optimization of resources allocation among varied projects quickly so as to minimize loss becomes an important problem.

In project resource allocating aspect, a project scheduling problem under resource constraint by genetic algorithms (GA) is studied in [1]. In project planning and scheduling aspect, problem of loading a finite capacity, stochastic and dynamic multi-project system is addressed in [2]. For project crashing problem under uncertainties, an approach based on ant colony optimization (ACO) metaheuristic and Monte Carlo (MC) simulation technique is proposed in [3]. A probabilistic background theory is developed for PERT in [4]. A stochastic framework defining a new solution that tries also to maintain the good performance of some other approaches that have been defined for the deterministic case is proposed in [5]. An alternative schedule risk quantification method is presented in [6]. A genetic algorithm based technique for conflict identification and resolution for project activities has been proposed in [7]. A discrete-event simulation approach with multiple-comparison procedure is presented to solve the stochastic resource-constrained project scheduling problem in [8]. A comprehensive proposal for project scheduling and control by applying fuzzy earned value is presented in [9]. Above research works benefit for project resource reallocating under uncertainty condition. However, optimization model of resources reallocation for project group under the precondition of resources supply scarcity needs to be studied profoundly.

\section{Optimization Model of Resources Allocation for Project Group}

Problem Description. Before construction, construction plan, scheduling scheme and resource allocation table for project group are usually worked out, the resource allocation scheme is optimal in theory. However, in practice, shortage of some key resources often appears. Thus, some working 
procedure will be postponed, the whole complete time of project will be postponed too. For project group composed of several projects, above status will often appear. Therefore, when resources are lacked, resources need to be reallocated among several projects in a reasonable way. To discuss problem easily, only one category resource is lacked on one working procedure.

\section{Variables Defining.}

$m$-number of projects in project group;

$n$-number of working procedures in each project;

$(i, j)$-working procedure $j$ in project $i$;

$r$ - category number of lacked resources;

$u_{i j k}$-demand quantity of resource $k$ on working procedure $j$ in project $i$;

$l_{i j k}$-practical quantity of resource $k$ on working procedure $j$ in project ${ }^{i}$;

$t_{i j}$ - standard working time of working procedure $j$ in project $i$;

$t_{i j}^{\prime}$ - practical working time of working procedure $j$ in project $i$ after resource quantity $l_{i j k}$ is allocated;

$\Delta t_{i j}$ - Free float of non key working procedure $j$ in project $i$;

$x_{i j}$-Boolean variable for judging whether working procedure $j$ in project $i$ is critical activity;

$s_{i j}^{\prime}$-the earliest starting time of procedure $j$ in project $i$ after resource quantity $l_{i j k}$ is allocated;

$P_{i j}^{\prime}$-the serial number set of predecessor activity of procedure $j$ in project $i$;

$\underline{\omega}_{k}$ - lower limit of allocating quantity of lacked resource $k$;

$\bar{\omega}_{k}$ - upper limit of allocating quantity of lacked resource $k$;

$c_{i}$-construction cost per day on critical activities for project $i$;

$c_{i f}$-construction cost per day on non-critical activities for project $i$.

Basic Analysis. On the basis of above variables defining, the resource diverge between practical resource quantity and demand resource quantity can be described as $u_{i j k}-l_{i j k}$, and $u_{i j k}-l_{i j k} \geq 0$. Resource diverge rate between practical resource quantity and demand resource quantity can be described as $\left(u_{i j k}-l_{i j k}\right) / u_{i j k}$. Time diverge of working procedure $j$ in project $i$, namely, delay time of working procedure $j$ in project $i$ is $t_{i j}\left(u_{i j k}-l_{i j k}\right) / u_{i j k}$. To distinguish critical activity and non critical activity, Boolean variable $x_{i j}$ is introduced and defined as formula (1).

$$
x_{i j}=\left\{\begin{array}{llc}
1 & (i, j) & \text { is critical activity } \\
0 & (i, j) & \text { else }
\end{array}\right.
$$

To ensure that the critical path does not change, delay time of wrking procedure on non critical path should be less than its free float, which can be described as formula (2).

$$
\left(1-x_{i j}\right) \frac{u_{i j k}-l_{i j k}}{u_{i j k}} \cdot t_{i j} \leq \Delta t_{i j}
$$

When resource quantity $l_{i j k}$ is allocated to working procedure $(i, j)$, the practical completing time $t_{i j}^{\prime}=t_{i j}\left(u_{i j k}-l_{i j k}\right) / u_{i j k}+t_{i j}$. As the allocated resource quantity $l_{i j k}$ is insufficient, for critical activity, tardiness caused by insufficient resource quantity $l_{i j k}$ will appear; for non-critical activity, practical completing time will increase, and the free float will be dectrased. In this paper, the critical activity path is supposed tho do not change, namely, tardiness time is less than free float. The remained free float is $\Delta t_{i j}-t_{i j}\left(u_{i j k}-l_{i j k}\right) / u_{i j k}$.

For each working procedure, the logical sequence should be ensured, only the predecessor activity is completed, the succeeding activity can start. The constraint relation among varied working procedure on varied project can be described as formula (3).

$$
s_{i j}^{\prime}-s_{h j}^{\prime} \geq i_{h j}^{\prime}, \quad \forall h \in P_{i j}^{\prime}
$$


On resource allocating, the allocated quantities constraint can be described as formula (4).

$$
\underline{\omega}_{k} \leq \sum_{i=1}^{m} \sum_{j=1}^{n} l_{i j k} \leq \bar{\omega}_{k}, k=1,2, \cdots, r
$$

Tardiness of working procedure will result in cost increasing. Once time delay appears, working procedure cost will be increased both on critical path and non critical path. However, construction cost per day is different for different project. Here, the working procedure cost on different working procedure is assumed to be same.

There are both critical activities and non-activities in each project, and there exists free float on non-activities. The construction cost per day on non-critical activities is usually less than that on critical activities. When allocated resource quantity $l_{i j k}$ is insufficient, free float will be reduced, and the extra increased cost is $\left(c_{i}-c_{i f}\right) t_{i j}\left(u_{i j k}-l_{i j k}\right) / u_{i j k}$.

Model Establishing. There are two optimization objectives, one is to minimize total tardiness of projects in project group, the other one is to minimize extra increased construction cost. As critical paths on every projects do not change, when calculating total tardiness of projects in project group, only time delay of critical activities are calculated. However, when calculating extra increased construction cost, both critical activities' extra construction cost and non- critical activities' extra construction cost will be summed. On above analysis, optimization model of resources allocation for project group under the precondition of resources supply scarcity is established as follows:

$$
\begin{aligned}
& \min \Delta T=\sum_{k=1}^{r} \sum_{i=1}^{m} \sum_{j=1}^{n} x_{i j}\left(1-\frac{l_{i j k}}{u_{i j k}}\right) t_{\mathrm{ij}} \\
& \min C= \sum_{k=1}^{r} \sum_{i=1}^{m} \sum_{j=1}^{n}\left[x_{i j} c_{i}\left(1-\frac{l_{i j k}}{u_{i j k}}\right) t_{i j}+\left(1-x_{i j}\right)\left(c_{i}-c_{i f}\right)\left(1-\frac{l_{i j k}}{u_{i j k}}\right) t_{i j}\right] \\
& \text { s.t. } \quad \underline{\omega}_{k} \leq \sum_{i=1}^{m} \sum_{j=1}^{n} l_{i j k} \leq \bar{\omega}_{k}, k=1,2, \cdots, r \\
& \quad\left(1-x_{i j}\right) \frac{u_{i j k}-l_{i j k}}{u_{i j k}} \cdot t_{i j} \leq \Delta t_{i j} \quad i=1,2, \cdots, m ; j=1,2, \cdots, n ; k=1,2, \cdots, r \\
& s_{i j}^{\prime}-s_{h j}^{\prime} \geq t_{h j}^{\prime}, \quad \forall h \in P_{i j}^{\prime}, \quad i=1,2, \cdots, m ; j=1,2, \cdots, n \\
& x_{i j}=0 \text { or } 1 \quad i=1,2, \cdots, m ; j=1,2, \cdots, n
\end{aligned}
$$

\section{Application Instance and Analysis}

The applied engineering project group is composed of three projects, namely, project A, project B and project $\mathrm{C}$. The construction plan and scheduling schemes of three projects have been worked out. However, during practical construction process, some unforeseen factors cause tardiness of some working procedures. To describe easily, only main body construction is considered. Construction plan and scheduling schemes and resources usage quantity plan is listed in table 1. The optimal resource reallocating scheme needs to be obtained.

For project $\mathrm{A}$, project $\mathrm{B}$ and project $\mathrm{C}$, extra cost caused by delaying of project completing time is respectively $c_{1}=1200 ¥$ per day, $c_{2}=1000 ¥$ per day and $c_{3}=1500 ¥$ per day.

For non-critical activity, its cost is lower when the working procedure is free than that when the working procedure is busy. For project $\mathrm{A}$, project $\mathrm{B}$ and project $\mathrm{C}$, extra cost caused by delaying of non-critical activity is respectively $c_{1 f}=500 ¥$ per day, $c_{2 f}=400 ¥$ per day and $c_{3 f}=700 ¥$ per day.

To ensure that each working procedure is finished successfully, supplied resource quantity for each working procedure is no less than $80 \%$ planned resource quantity.

Bring data in table 1 into optimization model of resources allocation for project group, the above model is presented in detail. The objective function expression is represented in detail as follows. 
Table 1 Construction plan and scheduling schemes and resources usage quantity plan

\begin{tabular}{|c|c|c|c|c|c|c|c|c|c|}
\hline Project & $\begin{array}{l}\text { Working } \\
\text { procedure }\end{array}$ & $\begin{array}{l}\text { predecessor } \\
\text { activity }\end{array}$ & $\begin{array}{c}\text { Planed } \\
\text { complement } \\
\text { time of } \\
\text { working } \\
\text { proceduring } \\
\text { [day] } \\
\end{array}$ & $\begin{array}{c}\text { Critical or } \\
\text { non-critical } \\
\text { activity(free float) }\end{array}$ & $\begin{array}{l}\text { Certain type } \\
\text { concrete iron } \\
\text { quantity[ton] }\end{array}$ & $\begin{array}{c}\text { Form } \\
\text { work } \\
\text { quantity } \\
{\left[\mathrm{m}^{3}\right]}\end{array}$ & $\left|\begin{array}{c}\text { concret } \\
\mathrm{e} \\
\text { deposit } \\
\text { worker }\end{array}\right|$ & $\begin{array}{l}\text { Floorslab } \\
\text { quantity }\end{array}$ & \begin{tabular}{|c|} 
Hoisting \\
worker
\end{tabular} \\
\hline \multirow{4}{*}{ A } & $\begin{array}{c}\text { Assembling } \\
\text { reinforcemen } \\
\mathrm{t}\end{array}$ & - & 64 & Critical activity & 50 & & & & \\
\hline & Shutering & - & 59 & $\begin{array}{c}\text { Non-critical } \\
\text { activity(free } \\
\text { float }=5)\end{array}$ & & 580 & & & \\
\hline & $\begin{array}{l}\text { Depositing } \\
\text { concrete }\end{array}$ & \begin{tabular}{|c|} 
Assembling \\
reinforcement, \\
shutering \\
\end{tabular} & 48 & Critical activity & & & 72 & & \\
\hline & $\begin{array}{l}\text { Installing } \\
\text { floorslab }\end{array}$ & $\begin{array}{c}\text { Depositing } \\
\text { concrete }\end{array}$ & 78 & Critical activity & & & & 7163 & \\
\hline \multirow{6}{*}{ B } & $\begin{array}{c}\text { Assembling } \\
\text { reinforcemen } \\
\mathrm{t}\end{array}$ & - & 56 & Critical activity & 40 & & & & \\
\hline & Shutering & $\begin{array}{c}\text { Assembling } \\
\text { reinforcement }\end{array}$ & 52 & Critical activity & & 460 & & & \\
\hline & Erecting door & - & 40 & $\begin{array}{l}\text { Non-critical } \\
\text { activity(free } \\
\text { float=12) }\end{array}$ & 0 & 0 & 0 & 0 & 0 \\
\hline & $\begin{array}{c}\text { Depositing } \\
\text { concrete }\end{array}$ & $\begin{array}{l}\text { Shutering, } \\
\text { erecting door }\end{array}$ & 58 & Critical activity & & & 66 & & \\
\hline & $\begin{array}{l}\text { Hoisting } \\
\text { floorslab }\end{array}$ & - & 48 & $\begin{array}{c}\text { Non-critical } \\
\text { activity(free } \\
\text { float }=10) \\
\end{array}$ & & & & & 56 \\
\hline & $\begin{array}{l}\text { Installing } \\
\text { floorslab }\end{array}$ & $\begin{array}{l}\text { Depositing } \\
\text { concrete, } \\
\text { Hoisting } \\
\text { floorslab } \\
\end{array}$ & 72 & Critical activity & & & & 6565 & \\
\hline \multirow{5}{*}{$\mathrm{C}$} & \begin{tabular}{|c|} 
Assembling \\
reinforcemen \\
$\mathrm{t}$
\end{tabular} & - & 70 & Critical activity & 55 & & & & \\
\hline & Shutering & $\begin{array}{c}\text { Assembling } \\
\text { reinforcement }\end{array}$ & 62 & Critical activity & & 640 & & & \\
\hline & $\begin{array}{l}\text { Hoisting } \\
\text { floorslab }\end{array}$ & - & 55 & $\begin{array}{l}\text { Non-critical } \\
\text { activity(free } \\
\text { float }=7 \text { ) }\end{array}$ & & & & & 66 \\
\hline & $\begin{array}{l}\text { Depositing } \\
\text { concrete }\end{array}$ & $\begin{array}{c}\text { Shutering, } \\
\text { hoisting } \\
\text { floorslab } \\
\end{array}$ & 68 & Critical activity & & & 80 & & \\
\hline & $\begin{array}{l}\text { Installing } \\
\text { floorslab }\end{array}$ & $\begin{array}{l}\text { Depositing } \\
\text { concrete }\end{array}$ & 76 & Critical activity & & & & 8132 & \\
\hline $\begin{array}{l}\text { Demand } \\
\text { quantity } \\
\text { sum } \\
\end{array}$ & & & & & 145 & 1680 & 218 & 21920 & 122 \\
\hline $\begin{array}{c}\text { Supply } \\
\text { quantity }\end{array}$ & & & & & 120 & 1450 & 190 & 18000 & 110 \\
\hline $\begin{array}{c}\text { Lower } \\
\text { limit or } \\
\text { resource } \\
\text { usage } \\
\end{array}$ & & & & & 95 & 1100 & 160 & 15000 & 90 \\
\hline
\end{tabular}

$\min \Delta T=\left(1-\frac{l_{111}}{50}\right) \cdot 64+\left(1-\frac{l_{133}}{72}\right) \cdot 48+\left(1-\frac{l_{144}}{7163}\right) \cdot 78+\left(1-\frac{l_{211}}{40}\right) \cdot 56+\left(1-\frac{l_{222}}{460}\right) \cdot 52+(1-$ $\left.\frac{l_{243}}{66}\right) \cdot 58+\left(1-\frac{l_{264}}{6565}\right) \cdot 72+\left(1-\frac{l_{311}}{55}\right) \cdot 70+\left(1-\frac{l_{322}}{640}\right) \cdot 62+\left(1-\frac{l_{343}}{80}\right) \cdot 68+\left(1-\frac{l_{354}}{8132}\right) \cdot 76$

$\min C=1200\left\{\left(1-\frac{l_{111}}{50}\right) \cdot 64+\left(1-\frac{l_{133}}{72}\right) \cdot 48+\left(1-\frac{l_{144}}{7163}\right) \cdot 78\right\}+(1200-500)\left(1-\frac{l_{122}}{580}\right) \cdot 59$ 


$$
\begin{aligned}
& +1000\left\{\left(1-\frac{l_{211}}{40}\right) \cdot 56+\left(1-\frac{l_{222}}{460}\right) \cdot 52+\left(1-\frac{l_{243}}{66}\right) \cdot 58+\left(1-\frac{l_{264}}{6565}\right) \cdot 72\right\}+(1000-400)\left(1-\frac{l_{255}}{56}\right) \cdot 48 \\
& +1500\left\{\left(1-\frac{l_{311}}{55}\right) \cdot 70+\left(1-\frac{l_{322}}{640}\right) \cdot 62+\left(1-\frac{l_{343}}{80}\right) \cdot 68+\left(1-\frac{l_{354}}{8132}\right) \cdot 76\right\}+(1500-700)\left(1-\frac{l_{335}}{66}\right) \cdot 55
\end{aligned}
$$

The constraint expression that critical path does not change is represented in detail as follows.

$$
59-\frac{59 l_{122}}{580} \leq 5 ; 48-\frac{48 l_{255}}{56} \leq 10 ; 55-\frac{55 l_{335}}{66} \leq 7 \text {. }
$$

The constraint expression that resource practical usage quantity is within its usage quantity span, namely, it is between the lower limit and upper limit of resource usage quantity. And this can be represented in detail as follows.

$$
\begin{aligned}
& 95 \leq l_{111}+l_{211}+l_{311} \leq 120 ; 1100 \leq l_{122}+l_{222}+l_{322} \leq 1450 ; 160 \leq l_{133}+l_{243}+l_{343} \leq 190 ; \\
& 15000 \leq l_{144}+l_{264}+l_{354} \leq 18000 ; 90 \leq l_{255}+l_{335} \leq 110 .
\end{aligned}
$$

The constraint expression that practical allocated resource quantity is no less than $80 \%$ palned resource quantity is represented in detail as follows.

$$
\begin{aligned}
& 50 \times 0.8 \leq l_{111} \leq 50 ; 580 \times 0.8 \leq l_{122} \leq 580 ; 72 \times 0.8 \leq l_{133} \leq 72 ; 7163 \times 0.8 \leq l_{144} \leq 7163 ; \\
& 40 \times 0.8 \leq l_{211} \leq 40 ; 460 \times 0.8 \leq l_{222} \leq 460 ; 66 \times 0.8 \leq l_{243} \leq 66 ; 6565 \times 0.8 \leq l_{264} \leq 6565 ; \\
& 56 \times 0.8 \leq l_{255} \leq 56 ; 55 \times 0.8 \leq l_{311} \leq 55 ; 640 \times 0.8 \leq l_{322} \leq 640 ; 80 \times 0.8 \leq l_{343} \leq 80 ; \\
& 8132 \times 0.8 \leq l_{354} \leq 8132 ; 66 \times 0.8 \leq l_{335} \leq 66 .
\end{aligned}
$$

The constraint expression that logical relation among varied working procedures is represented in detail as follows.

$$
\begin{aligned}
& s_{13}^{\prime}-s_{11}^{\prime} \geq 64+\left(64-\frac{64 l_{111}}{50}\right) ; s_{13}^{\prime}-s_{12}^{\prime} \geq 59+\left(59-\frac{59 l_{122}}{580}\right) ; s_{14}^{\prime}-s_{13}^{\prime} \geq 48+\left(48-\frac{48 l_{133}}{72}\right) ; \\
& s_{22}^{\prime}-s_{21}^{\prime} \geq 56+\left(56-\frac{56 l_{211}}{40}\right) ; s_{24}^{\prime}-s_{22}^{\prime} \geq 52+\left(52-\frac{52 l_{211}}{460}\right) ; s_{24}^{\prime}-s_{23}^{\prime} \geq 40 ; \\
& s_{26}^{\prime}-s_{24}^{\prime} \geq 58+\left(58-\frac{58 l_{243}}{66}\right) ; s_{26}^{\prime}-s_{25}^{\prime} \geq 48+\left(48-\frac{48 l_{255}}{56}\right) ; s_{32}^{\prime}-s_{31}^{\prime} \geq 70+\left(70-\frac{70 l_{311}}{55}\right) ; \\
& s_{34}^{\prime}-s_{32}^{\prime} \geq 62+\left(62-\frac{62 l_{322}}{640}\right) ; s_{34}^{\prime}-s_{33}^{\prime} \geq 55+\left(55-\frac{55 l_{335}}{640}\right) ; s_{35}^{\prime}-s_{34}^{\prime} \geq 68+\left(68-\frac{68 l_{343}}{80}\right) .
\end{aligned}
$$

The obtained optimal solution is represented in detail as follows.

$$
\left(l_{111}, l_{122}, l_{133}, l_{144}, l_{211}, l_{222}, l_{243}, l_{255}, l_{264}, l_{311}, l_{322}, l_{335}, l_{343}, l_{354}\right)=(40.00,530.85,57.60,5730.40,32.00 \text {, }
$$
$368.00,52.80,44.80,5252.00,48.00,551.15,65.20,79.60,7017.60)$.

As numbers of workers should be integers, $l_{133}=57, l_{243}=53, l_{343}=80, l_{255}=45, l_{335}=65$. The obtained optimal objection function value $\min \Delta T=113.76, \min C=145225$.

Although some resources are lacked in project group, the optimal solution scheme with minimal completing time delay and construction cost is obtained by above optimization model of resources allocation for project group. The model is fitful to implement scientific reallocating of limited resources among projects within project group, and the limited resources can be used effectively so as to minimize the loss caused by resources lacking.

\section{Summary}

Optimization problem of resources reallocating under limited resources quantities is one of a hotspot problem for project group. Optimization reallocating purpose is to improve usage efficiency of resources, optimize completing working time and reduce construction cost. For resources reallocating problem under limited resources quantities, there are many working procedure in each project, and there exist rigid logic relations among varied working procedures. Related resources supplying is demanded for each working procedure. There exists common demand to certain category resource for same working procedure in different working procedures. If supplied resources are 
insufficient, without reasonable resources reallocating, construction scheduling schemes of varied projects will be disturbed, collision even shutdown will come into being for some projects.

According to the feature of resources reallocating problem within project group under limited resources, minimizing tardiness of working completing time and extra increased construction cost is taken as optimization objective, optimization model of resources reallocation is established by programming theory.

Although resources are lacked, reasonable resources usage and minimized loss can be implemented by optimization resources reallocating. When similar problems appear in practical engineering, above model can be employed to reallocating resources in quick way. Optimal decision can be maken out within least time so as to provide efficient supporting for managers during construction. To describe easily, only one category resource is assumed to be lacked for each working procedure. However, in practical construction, lacking several category resources are lacked for each working procedure will also happens, optimization model in this case will be studied profoundly. For resource allocating or reallocating problem, introducing complex modeling and intelligent optimization technique will be an important trend in this research domain.

\section{Acknowledgements}

This work was financially supported by the Project from Ministry of Housing and Urban-Rural Development of the People's Republic of China(2014-R3-014), Science Research Program of Liaoning Province Education Administration: Liaoning city public safety management by E-CBR (W2014084) \& Research on the industry-university-research-user cooperative innovation mechanism of the market oriented research in Liaoning (W2014085), Work Safety Project of State Administration (2013-13), Shenyang Scientific and Technological Planning (F13-317-5-12; F14-230-5-19; F15-198-5-15) and Science Research Foundation of Shenyang Jianzhu University (2014035).

\section{References}

[1] S.Hartmann: A self-adapting genetic algorithm for project scheduling under resource constraints: Naval Re-search LogisticsVol. 49 (2002), p. 433-448

[2]Izack Cohen, Boaz Golany, Avraham Shtub: Managing Stochastic, Finite Capacity, Multi-Project Systems through the Cross-Entropy Methodology: Annals of Operations Research Vol. 134 (2005) p. 183-199

[3]Abdollah Aghaie, Hadi Mokhtari: Ant colony optimization algorithm for stochastic project crashing problem in PERT networks using MC simulation: The International Journal of Advanced Manufacturing Technology Vol. 45(2009), p. 1051-1067

[4]Davaadorjin Monhor: A new probabilistic approach to the path criticality in stochastic PERT: Central European Journal of Operations Research Vol. 19 (2011), p. 615-633

[5]Javier Castro, Daniel Gómez, Juan Tejada: Allocating slacks in stochastic PERT network: Central European Journal of Operations Research Vol. 22 (2014), p. 37-52

[6]Jong-Ho Ock, Seung-Heon Han: Measuring risk-associated activity's duration: A fuzzy set theory application: KSCE Journal of Civil Engineering Vol. 14 (2010) , p. 663-671

[7]Muhammad Ramzan, Arfan Jaffar, Amjad Iqbal, Sajid Anwar, Abdul Rauf, Arshad Ali Shahid: Project scheduling conflict identification and resolution using genetic algorithms (GA): Telecommunication Systems Vol. 51 (2012), p. 167-175

[8]Shiqi Li, Yan Jia, Junfeng Wang: A discrete-event simulation approach with multiple-comparison procedure for stochastic resource-constrained project scheduling: The International Journal of Advanced Manufacturing Technology Vol. 63 (2012), p. 65-76 
[9]José Luís Ponz-Tienda, Eugenio Pellicer, Víctor Yepes: Complete fuzzy scheduling and fuzzy earned value management in construction projects: Journal of Zhejiang University SCIENCE A Vol. 13 (2012), p. 56-68 